Rev. Bras. Saúde Prod. Anim., Salvador, v.16, n.1, p.66-72 jan./mar., 2015 http://www.rbspa.ufba.br

\title{
Simulação de condições de uso de quaternário de amônio frente amostras de Salmonella Hadar isoladas de carcaças de frango
}

\author{
Simulation of the conditions of use of quaternary ammonium in samples of \\ "Salmonella" Hadar isolated from poultry carcasses
}

\section{CAMILOTTI, Elisar ${ }^{1}$; ROCHA, Silvio Luis da Silveira ${ }^{2}$; TEJKOWSKI, Thiago Moreira $^{2}$; MORAES, Hamilton Luiz de Souza ${ }^{2}$; SALLE, Carlos Tadeu Pippi ${ }^{2}$; AVANCINI, César Augusto Marchionatti ${ }^{3 *}$}

\author{
${ }^{1}$ Empresa de Assistência Técnica e Extensão Rural, Centro de Pesquisa e Diagnóstico em Patologia \\ Aviária, Porto Alegre, Rio Grande do Sul, Brasil. \\ ${ }^{2}$ Universidade Federal do Rio Grande do Sul, Faculdade de Veterinária, Centro de Pesquisa e Diagnóstico \\ em Patologia Aviária, Porto Alegre, Rio Grande do Sul, Brasil. \\ ${ }^{3}$ Universidade Federal do Rio Grande do Sul, Faculdade de Veterinária, Departamento de Medicina \\ Veterinária Preventiva, Porto Alegre, Rio Grande do Sul, Brasil. \\ *Endereço para correspondência: cesar.avancini@ufrgs.br
}

\section{RESUMO}

Para impedir a dispersão de microrganismos patogênicos ao longo da cadeia avícola medidas de biosseguridade são adotadas, sendo a desinfecção procedimento obrigatório e $\mathrm{o}$ composto químico cloreto de benzalcônio (quaternário de amônio) largamente usado para essa finalidade. Devido ao fato de que parte das criações brasileiras localizam-se em regiões com grande amplitude térmica, o mesmo ocorrendo entre as diferentes áreas e secções de matadouros-frigoríficos, executou-se este experimento para verificar a atividade desse desinfetante simulando condições de uso frente a 33 isolados de Salmonella Hadar. Pelo teste de suspensão observou-se a inativação bacteriana sob as variáveis concentração (100 e 200 ppm), temperatura $\left(20 \pm 2{ }^{\circ} \mathrm{C}\right.$ e $\left.8 \pm 2{ }^{\circ} \mathrm{C}\right)$, carga de matéria orgânica ( 1 e $3 \%$ ) e tempos de contato (5, 10 e 20 minutos). Como resultados, a $20 \pm 2$ ${ }^{\circ} \mathrm{C}$ todos os isolados foram inativados nas duas concentrações e cargas orgânicas após 5 minutos de contato. Sob temperatura de $8 \pm 2{ }^{\circ} \mathrm{C}$ o desinfetante teve sua atividade comprometida, tendo isolados bacterianos sobrevivido sob todas as variáveis de confronto $(33,3 \%$ frente $100 \mathrm{ppm} \mathrm{e} \mathrm{6,1 \%} \mathrm{frente} 200 \mathrm{ppm})$. Quanto menor a concentração do desinfetante e maior carga orgânica, maior o número de isolados viáveis. Conclui-se que, nas condições do experimento, o cloreto de benzalcônio foi capaz de inativar todos os isolados do sorovar de
Salmonella confrontados, podendo ser empregado nos procedimentos de desinfecção. No entanto, a baixa temperatura ambiente é fator de limitação na indicação de seu uso.

Palavras-chave: cloreto de alquil dimetil benzil amônio, cloreto de benzalcônio, desinfecção, avicultura, matadouro-frigorífico

\section{SUMMARY}

Biosafety measures are adopted in order to avoid the spreading of pathogenic microorganisms along the poultry chain, with disinfection being a mandatory procedure and the chemical compound benzalkonium chloride (quaternary ammonium) widely used for this purpose. Due to the fact that part of the farming in Brazil is located in areas with a great thermal amplitude, which is also the case among the different areas and sections of slaughterhouses, we performed an experiment to verify the activity of this disinfectant, simulating conditions of use with 33 Salmonella Hadar isolates. Using the test suspension, the inactivation of the bacteria was monitored under different concentrations (100 and $200 \mathrm{ppm})$, temperatures $\left(20 \pm 2{ }^{\circ} \mathrm{C}\right.$ and $\left.8 \pm 2{ }^{\circ} \mathrm{C}\right)$, organic matter loading ( 1 and $3 \%$ ) and contact times (5, 10 and 20 minutes). As a result, all isolates in the two concentrations and organic loading were inactivated at $20 \pm 2{ }^{\circ} \mathrm{C}$ after a contact time of 5 
Rev. Bras. Saúde Prod. Anim., Salvador, v.16, n.1, p.66-72 jan./mar., 2015 http://www.rbspa.ufba.br

minutes. At a temperature of $8 \pm 2{ }^{\circ} \mathrm{C}$, the disinfectant's activity was affected, with bacterial isolates surviving under all adverse variables $(33,3 \%$ in front of $100 \mathrm{ppm}$ and $6,1 \%$ in front of $200 \mathrm{ppm})$. Under the conditions of the experiment, our conclusion is that benzalkonium chloride was able to inactivate all isolates of the Salmonella serovars found and, therefore, it can be used in disinfection procedures. However, a low room temperature is a factor that limits indicating its use.

Keywords: alkylbenzyldimetylammonium cloride, benzalkonium chloride, disinfection, aviculture, slaughterhouse

\section{INTRODUÇÃO}

Os sistemas de produção intensivos adotados na avicultura industrial estão baseados na alta densidade animal em granjas. Por consequência sanitária temse o favorecimento da instalação e dispersão de agentes patógenos, que podem estar presentes tanto nos ambientes de produção animal quanto nos de industrialização dos produtos avícolas. Entre os agentes potencialmente patogênicos a Salmonella tem grande destaque, pois além de causar prejuízos em função de enfermidade provocada nas aves é considerada uma das principais bactérias transmissíveis comuns entre animais e humanos.

Dentro do gênero Salmonella e dos sorotipos não espécie-específicos (paratíficos ou zoonóticos) o sorovar Hadar tem merecido atenção, estando entre os mais isolados no mundo (HERIKSTAD et al., 2002; ECHEITA et al., 2002; LENGLET, 2005).

O controle da Salmonella na avicultura não é simples, tendo-se em vista que inúmeras são as fontes de infecção em um sistema de produção, sendo um efetivo programa de higienização, como procedimento de biossegurança (MARTINS, 2001), a base para a manutenção da saúde animal. Kuana
(2009) afirma que uma avaliação criteriosa dos processos de limpeza e desinfecção dos ambientes é de extrema necessidade, pois eventuais falhas na inativação dos agentes infecciosos podem ocorrer devido à má limpeza das superfícies ou outros fatores que interferem na eficiência da desinfecção, ou ainda podendo estar ligado a mecanismos de resistência de alguns microrganismos.

Devido ao fato de que parte das criações brasileiras localiza-se em regiões com grande amplitude térmica, e que o composto químico cloreto de benzalcônio (quaternário de amônio) é um desinfetante largamente usado nesses ambientes, bem como nos matadourosfrigoríficos, executou-se experimento para monitorar e verificar sua atividade simulando condições de uso frente a 33 isolados de Salmonella Hadar.

\section{MATERIAL E MÉTODOS}

Os 33 isolados de Salmonella Hadar utilizados no estudo pertenciam a bacterioteca do Centro de Diagnóstico em Patologia Aviária (CDPA/Faculdade de Veterinária/UFRGS). Os mesmos foram isolados de carcaças (20) e cortes (13) de frangos em matadouros-frigoríficos no estado do Rio Grande do Sul e identificados no Instituto Oswaldo Cruz (FIOCRUZ). A segurança taxonômica esteve entre os motivos da seleção dos isolados. Na composição da amostra observou-se para não selecionar isolados que pudessem ser da mesma fonte de contaminação.

O composto cloreto de benzalcônio - nome químico alkylbenzyldimetylammonium cloride - pertence ao grupo químico quaternário de amônio (ANVISA, 2011). Foi adquirido de forma purificada e acompanhado de laudo técnico. As concentrações testadas 100ppm e 
200ppm foram escolhidas por referência de uso indicadas em produtos comerciais que utilizam esse princípio ativo na formulação.

Os testes foram realizados sob duas condições de temperatura: $20 \pm 2^{\circ} \mathrm{C}$ e 8 $\pm 2^{\circ} \mathrm{C}$. As temperaturas ambiente foram obtidas por uso de ar condicionado e de geladeira, controladas com termômetro de máxima e mínima. Para aclimatação, os materiais foram deixados nos ambientes por quatro horas antes dos experimentos.

Para simular a matéria orgânica presente no ambiente avícola e de matadouros foi usada albumina sérica bovina (soro bovino estéril - Sorali ${ }^{\circledR}$ ). Assim, antes do início dos testes, adicionou-se aos tubos de ensaio com o desinfetante já diluído em água destilada estéril o soro bovino, de modo a formar as cargas orgânicas de $1 \%$ e $3 \%$. O método de avaliação da atividade antibacteriana foi o de diluição, com teste de suspensão, conforme descrito na Portaria $\mathrm{N}^{\mathrm{o}}$ 101, de 11 de agosto de 1993 - Métodos Analíticos para Controle de Produtos de Origem Animal e seus Ingredientes - 28 -Verificação da Eficiência de Desinfetantes (BRASIL, 1993).

Os tubos de ensaio com BHI (Merck ${ }^{\circledR}$ ) usados para replique após tempos de contato desinfetante $v s$ bactéria estavam acrescidos de neutralizador, na seguinte composição: $3 \%$ de polisorbato $80,0,3$ $\%$ de lecitina e $0,1 \%$ de histidina. Cada tubo de ensaio contendo o desinfetante já diluído de acordo com as concentrações determinadas e com matéria orgânica, quando em diferentes condições de temperatura, recebeu $0,1 \mathrm{~mL}$ da amostra bacteriana ajustada para densidade populacional de confronto em $10^{6}$ a $10^{7} \mathrm{UFC} / \mathrm{mL}$. Por meio de alça bacteriológica de $10 \mu \mathrm{L}$, após tempos de contato cronometrados de 5,10 e 20 minutos, três alíquotas foram retiradas e inoculadas em três diferentes tubos de ensaio contendo meio de cultura BHI adicionados com neutralizador. Esses tubos foram agitados, incubados a $37^{\circ} \mathrm{C}$ e observados nos períodos de 24, 48, 72 e 96 horas. Como critério para interpretação dos resultados, testes positivos (bactéria inativada) foram considerados quando não se verificou crescimento bacteriano (tubos sem turvação, formação de película na superfície ou de precipitado).

Realizou-se a confirmação da ausência de contaminação nos tubos em que houve crescimento bacteriano (bactéria ativa) por semeadura em meio seletivo XLD (Xilose Lysine Deoxicholate Merck $\left.^{\circledR}\right)$.

\section{RESULTADOS E DISCUSSÃO}

Os testes realizados a temperatura de $20 \pm 2^{\circ} \mathrm{C}$, concentração de $100 \mathrm{ppm} \mathrm{e}$ tempo de contato de 5 minutos mostraram $100 \%$ dos isolados de Salmonella Hadar inativados pelo cloreto de benzalcônio, independente da carga de matéria orgânica (Tabela 1).

$\mathrm{Na}$ concentração acima citada, os ensaios realizados a temperatura de $8 \pm 2^{\circ} \mathrm{C}$ mostraram que mesmo após 20 minutos de contato o desinfetante não foi capaz de inativar todos os isolados de Salmonella Hadar. Nos testes realizados com $1 \%$ de matéria orgânica $12,1 \%$ precisaram de 20 minutos de contato com o cloreto de benzalcônio para serem inativadas, e $15,2 \%$ dos 33 isolados permaneceram ativos. Quando a atividade do desinfetante foi avaliada sob a carga mais elevada de matéria orgânica, o número de isolados que permaneceram ativos foi de $33,3 \%$ e necessitaram 20 minutos de contato para inativar $36,3 \%$ das amostras. 
Rev. Bras. Saúde Prod. Anim., Salvador, v.16, n.1, p.66-72 jan./mar., 2015 http://www.rbspa.ufba.br ISSN 15199940

Tabela 1. Amostras de Salmonella Hadar inativadas pelo cloreto de benzalcônio (quaternário de amônio) na concentração de 100 ppm, por tempo de contato, frente a diferentes condições de temperatura e matéria orgânica

\begin{tabular}{ccccc}
\hline \multirow{2}{*}{ Condição $(\mathrm{T}+\mathrm{MO})$} & \multicolumn{3}{c}{ Tempo de contato (minutos) } & \multirow{2}{*}{ Não inativadas } \\
\cline { 2 - 4 } & 5 & 10 & 20 & - \\
\hline $20 \pm 2^{\circ} \mathrm{C}$ e $1 \%$ & 33 & - & - & 5 \\
$8 \pm 2^{\circ} \mathrm{C}$ e $1 \%$ & 15 & 9 & - & - \\
$20 \pm 2^{\circ} \mathrm{C}$ e $3 \%$ & 33 & - & 12 & 11 \\
$8 \pm 2^{\circ} \mathrm{C}$ e $3 \%$ & 1 & 9 & \\
\hline
\end{tabular}

$\mathrm{MO}=$ concentração de matéria orgânica (albumina bovina); $\mathrm{T}=$ temperatura de uso do desinfetante durante os ensaios.

Sobre a atividade do cloreto de benzalcônio, em temperatura constante e na ausência de matéria orgânica, Borowsky et al. (2006), Machado et al. (2010) e Fazlara \& Ekhtelat (2012) já haviam informado sobre a capacidade bactericida desse desinfetante sobre o gênero Salmonella. Confirma-se, agora, a atividade sobre o sorovar Hadar, do qual se infere não apresentar resistência intrínseca ao desinfetante.

No que se refere à influência da matéria orgânica na atividade de desinfetantes, usando como modelo Acinetobacter spp, Kawamura-Sato et al. (2008) observaram que o cloreto de benzalcônio teve sua ação bactericida reduzida à medida que os ensaios contemplavam cargas mais elevadas (até 3\%) de soro bovino, em uma temperatura constante $20^{\circ} \mathrm{C}$. No entanto essa redução começou a ocorrer apenas quando o desinfetante foi testado em concentrações menores que $100 \mathrm{ppm} / \mathrm{L}$, o que coincide com o que foi observado neste trabalho em que, na temperatura de $20 \pm 2^{\circ} \mathrm{C}$, a matéria orgânica não afetou a atividade antibacteriana

Nos ensaios em que o desinfetante foi avaliado na concentração de 200 ppm e temperatura de $20 \pm 2^{\circ} \mathrm{C}$, assim como ocorreu na concentração de 100 ppm, todos os isolados foram inativados com 5 minutos de contato, independente da carga orgânica (Tabela 2).

Tabela 2. Amostras de Salmonella Hadar inativadas pelo cloreto de benzalcônio (quaternário de amônio) na concentração de 200 ppm, por tempo de contato, frente a diferentes condições de temperatura e matéria orgânica

\begin{tabular}{lcccc}
\hline \multirow{2}{*}{ Condição $(\mathrm{T}+\mathrm{MO})$} & 5 & 10 & 20 & \multirow{2}{*}{ Não Inativadas } \\
\cline { 2 - 5 } & 33 & - & - & - \\
\hline $20 \pm 2{ }^{\circ} \mathrm{C}$ e $1 \%$ & 30 & 1 & 2 & - \\
$8 \pm 2{ }^{\circ} \mathrm{C}$ e $1 \%$ & 33 & - & - & - \\
$20 \pm 2{ }^{\circ} \mathrm{C}$ e $3 \%$ & 15 & 11 & 5 & 2 \\
$8 \pm 2{ }^{\circ} \mathrm{C}$ e $3 \%$ & orgânica & (albumina bovina); & $\mathrm{T}=$ temperatura de uso do \\
\hline $\mathrm{MO}=$ concentração de matéria & &
\end{tabular}

A eficácia diminuiu quando a temperatura de confrontação foi reduzida para $8 \pm 2^{\circ} \mathrm{C}$. Mesmo tendo-se observado resultados esperados de que maior concentração do desinfetante inativaria maior número de isolados bacterianos, $6,1 \%$ não foram inativadas quando submetidas as condições de 
Rev. Bras. Saúde Prod. Anim., Salvador, v.16, n.1, p.66-72 jan./mar., 2015 http://www.rbspa.ufba.br ISSN 15199940

menor temperatura e maior carga orgânica $\left(8 \pm 2^{\circ} \mathrm{C}\right.$ e $3 \%$, respectivamente).

Pode-se considerar que há efeito da temperatura sobre a ação de sanitizantes, em concordância com Tucan (1993) ao citar que o quaternário de amônio em 200ppm, e também o iodóforo a $50 \mathrm{ppm}$ foram ineficazes frente a algumas amostras de Listeria spp sob baixas temperaturas (intervalo entre $2^{\circ} \mathrm{C}$ até $15^{\circ} \mathrm{C}$ ), enquanto foram eficazes a $25^{\circ} \mathrm{C}$.

Também Taylor et al. (1999), em ensaios para avaliar 10 diferentes grupos químicos desinfetantes frente as bactérias Escherichia coli O157:H7 e Pseudomonas aeruginosa, usando como variáveis independentes os fatores concentração, matéria orgânica e temperatura, observaram que os pertencentes ao grupo quaternários de amônia (sem informar o composto químico) e os anfóteros tiveram a atividade antimicrobiana reduzida quando submetido a temperatura teste de $10^{\circ} \mathrm{C}$, em comparação aos testes realizados a $20^{\circ} \mathrm{C}$. Portanto, assim como verificado no presente estudo, o cloreto de benzalcônio tem sua capacidade antibacteriana reduzida quando submetido a temperaturas de uso de $20 \pm 2^{\circ} \mathrm{C}$ a $8 \pm 2^{\circ} \mathrm{C}$ graus. Observa-se também que na temperatura de confronto de $8 \pm 2^{\circ} \mathrm{C}$ graus as cargas de matéria orgânica passaram a interferir na atividade biocida (quanto mais alta a carga, maior a interferência).

Kich et al. (2004) observaram que o cloreto de alquil dimetil benzil amônio testado frente a uma amostra padrão de Salmonella Typhimurium, na presença e ausência de matéria orgânica, sob duas diferentes temperaturas $\left(10\right.$ e $\left.30^{\circ} \mathrm{C}\right)$, em tempo de contato de 15 minutos, foi eficaz nas duas temperaturas e ausência da matéria orgânica, mas não em 2 das 5 repetições, na sua presença, independente da temperatura. No entanto, deve-se pontuar que a concentração testada foi de 400ppm. Os resultados obtidos no estudo agora apresentado permitem verificar que a concentração de 200ppm do desinfetante sofreu menor interferência da temperatura e da matéria orgânica conjugadas, o que pode estar de acordo com Kich et al. (2004). Também Tucan (1993) apontou que a atividade antimicrobiana fica aumentada com o incremento da concentração e tempo de contato.

Nas condições do experimento, o cloreto de benzalcônio foi capaz de inativar todos os isolados do sorovar de Salmonella confrontados, podendo ser empregado nas concentrações de $100 \mathrm{ppm}$ ou 200ppm nos processos de desinfecção, sendo, no entanto, a temperatura de $8 \pm 2^{\circ} \mathrm{C}$ graus fator de limitação de sua atividade.

A matéria orgânica, nas duas cargas, isoladamente, não promoveu interferência na atividade biocida do desinfetante quando a temperatura estava em $20 \pm 2^{\circ} \mathrm{C}$. No entanto, quando a confrontação ocorreu na temperatura $8 \pm 2^{\circ} \mathrm{C}$ a matéria orgânica influenciou na atividade: quanto maior a carga, maior a interferência. Por outro lado, quanto maior a concentração do desinfetante, menor a interferência.

\section{REFERÊNCIAS}

AGÊNCIA NACIONAL DE VIGILÂNCIA SANITÁRIA/BR ANVISA. Monografias autorizadas C52 - Cloretos de Benzalcôneo.

Disponível em:

$<$ http://portal.anvisa.gov.br/wps/content /Anvisa+Portal/Anvisa/Inicio/Agrotoxic os+e+Toxicologia/Assuntos+de+Interes se/Monografias + de + Agrotoxicos $>$.

Acesso: 26 set. 2013. 
Rev. Bras. Saúde Prod. Anim., Salvador, v.16, n.1, p.66-72 jan./mar., 2015 http://www.rbspa.ufba.br ISSN 15199940

BOROWSKY, L.M.; BESSA, M.C.; CARDOSO, M.R.I.; AVANCINI, C.A.M. Sensibilidade e resistência de amostras de Salmonella Typhimurium isoladas de suínos abatidos no Rio Grande do Sul/Brasil frente aos desinfetantes químicos quaternário de amônio e iodofor. Ciência Rural, v.36, n.5, p.1474-1479, 2006.

BRASIL, Portaria $\mathrm{n}^{\circ} 101$, de 17 de agosto de 1993. Ministério da Agricultura, Pecuária e Abastecimento. Métodos de Análise Microbiológica para Alimentos. Diário Oficial [Da República Federativa do Brasil], Brasília, 17 de agosto de 1993, Seção I, 1993. p.11937-11945,

ECHEITA, M.A.; HERRERA, S.; GARANIZAR, J.; USERA, M.A. Multiplex- PCR based detection and identification of most common Samonella second-phase flagellar antigens. Research in Microbiology, v.153, p.107-113, 2002.

FAZLARA, A.; EKHTELAT, M. The disinfectant effects of benzalkonium chloride on some important foodborne pathogens. American-Eurasian Journal of Agricultural \& Environmental Sciences, v.12, n.1, p.23-29, 2012

HERISKTAD, H.; MOTARJEMI, Y.; TAUXE, R.V. Salmonella surveillance: a global survey of public health serotyping. Epidemiology and Infection, v.129, n.1, p.1-8, 2002.

KAWAMURA-SATO, K.; WACHINO, J.; KONDO, T.; ITO, H.; ARAKAWA, Y. Reduction of disinfectant bactericidal activities in clinically isolated Acinetobacter species in the presence of organic material. Journal of Antimicrobial Chemotherapy, v.61, n.3, p.568-576, 2008.
KICH, J.D.; BOROWSKY, L.M.; SILVA, V.S.; RAMENZONI, M.; TRIQUES, N.; KOOLER, F.L.; CARDOSO, M.R.I. Avaliação da atividade antibacteriana de seis desinfetantes comerciais frente a amostras de Salmonella Typhimurium isoladas de suínos. Acta Scientiae Veterinariae, v.32, n.1, p.33-39, 2004.

KUANA, S.L. Limpeza e desinfecção de instalações avícolas. In: BERCHIERI JUNIOR, A.; SILVA, E.N.; DI FÁBIO, J.; SESTI, L.; ZUANAZE, M.A.F. Doenças das aves. 2.ed. Campinas, SP: FACTA, 2009. p.21-38.

LENGLET, A. National Epidemiological Surveillance Network of Spain. E-alert 9 August: over 2000 cases so far in Salmonella Hadar outbreak in Spain associated with consumption of pre-cooked chicken. Eurosurveillance, v.10, n.32, p.2770, 2005.

MACHADO, T.R.M.; MALHEIROS, P.S.; BRANDELLI, A.; TONDO, E.C. Avaliação da resistência de Salmonella à ação de desinfetantes ácido peracético, quaternário de amônio e hipoclorito de sódio. Revista do Instituto Adolfo Lutz, v.69, n.4, p.475-481, 2010.

MARTINS, N.R.S. Influenza aviária: uma revisão dos últimos dez anos. Revista Brasileira de Ciência Avícola, v.3, p.97-140, 2001.

TAYLOR, J.H.; ROGERS, B.G.; HOLAH, J.T.A comparison of the bactericidal efficacy of 18 disinfectants used in the food industry against Escherichia coli O157:H7 and Pseudomonas aeruginosa at 10 and 20 ${ }^{\circ} \mathrm{C}$. Journal of Applied Microbiology, v.87, n.5, p.718-725, 1999. 
Rev. Bras. Saúde Prod. Anim., Salvador, v.16, n.1, p.66-72 jan./mar., 2015 http://www.rbspa.ufba.br ISSN 15199940

TUNCAN, E.U. Effect of cold

temperature on germicidal efficacy of

quaternary ammonium compound,

iodophor, and chlorine on Listeria.

Journal of Food Protection, v.56,

p.1029-1033, 1993.

Data de recebimento: 18/12/2013

Data de aprovação: 16/03/2015 